\title{
The Cooperation of Educational Partners in the Management of the "Cyberbullying" at Nonmetropolitan Albanian Adolescents
}

\author{
Msc. Marsela Shehu (PhD. Student) \\ Sports University of Tirana, Department of Social Sciences and Education \\ marsela.shehu@gmail.com \\ Prof. As. Dr. Zenel Orhani \\ University of Tirana, Department of Pedagogy and Psychology \\ zeorhani@yahoo.com
}

\section{Doi:10.5901/ajis.2015.v4n3s1p494}

\section{Abstract}

\begin{abstract}
Educational partners, more important are teachers and parents are considered as one of the main elements in the management of Cyberbullying in the school environment and not only for their child's safety. The aim of the study is to evidence the cooperative elements among parents, teachers and students during misuse of the Internet and its functions and violence caused by the technology. The sample of the study includes 200 pupils aged 15-19, 55 Male and 145 Female from High School's Elbasan. Instrument used was "Student Needs Assessment Survey" APPENDIX E by N. E. Willard (2007). The questionnaire was modified and adapted by the authors and contains 20 items. The statistical data processing was performed by SPPS statistical program, version 20. Cronbach's Alpha 0.751 were used to assess the reliability of the instrument. Relying situated in the role of one who puts pressure on the Internet to others, and the role of the person on whom are pressured by the results obtained we note that students are not included in any of above mentioned role. For the psycho-pedagogical point of view we can say that viewed a positive relationship and not only communication between adolescents and their parents, but also among school staff. Students claim that their peers do not feel pressured by others and also students affirm that they are not aware of any material posted on the Internet that denigrates the image of a school staff member.
\end{abstract}

Keywords: cyberbullying, adolescents, parent, school staff, communication tools.

\section{Introduction}

Adolescents are currently the defining users of the Internet. They spend more time online than adults do. When online communication technologies, such as e-mail and chat rooms, became popular in the 1990s, several authors believed that these technologies would reduce adolescents' social connectedness and well-being. ${ }^{1}$

It refers to adolescents' relationships with others such as friends, family members etc. At the time, it was assumed that the Internet motivates adolescents to form superficial online relationships with strangers that are less beneficial than their real world relationships and time spent with online strangers occurs at the expense of time spent with existing relationships. The virtual world in the Internet is not unreal, because online relationships still involve real life - friends met online can be contacted in real life. ${ }^{2}$

Cyberbullying is deliberately using digital media to communicate false, embarrassing, or hostile information about another person. It is the most common online risk for all teens and is a peer-to-peer risk. Although "online harassment" is often used interchangeably with the term "cyberbullying," it is actually a different entity. On the other hand, cyberbullying can occur to any young person online and can cause profound psychosocial outcomes including depression, anxiety,

\footnotetext{
1 Valkenburg M. P., \& Peter J. (2009). Social Consequences of the Internet for Adolescents: A Decade of Research. Current Directions in Psychological Science Vol. 18, No. 1,1-5 pp.

${ }^{2}$ Chao, C.M.; Yu, T.K. \& Cheng, B.W. (2013). Modeling predictors of adolescents' attitude towards a cyber lives index. Malaysian Journal of Library and Information Science, Vol. 18, No. 1, 87 - 104 pp.
} 
severe isolation and tragically suicide. ${ }^{3}$

As to power imbalance, many cybervictims experience helplessness if their bully remains anonymous and often there is no getting away from cyberbullying, as technology based interactions can take place any time and in any place. Occurs most often when children are at home, but it can also take place during school. Another aspect distinguishing cyberbullying is anonymity with cyberbullies able to remain unidentified behind their computer screen or cell phone and to aggress against their victims even when they are physically far away. This physical distance may help to disinherits cyberbullies making it easier to say or write things they normally would not in a face-to-face interaction. ${ }^{4}$

Cyberbullying may be transmitted via e-mail, social networking sites, chat rooms, message boards, instant messaging or cell phones. Most cyberbullying categories are: Flaming, Harassment and stalking, Denigration, Impersonation, Outing and trickery, Exclusion. 56

The school, as well as parent and community members can help to facilitate parent and community outreach and education. Information should include an overview of the concerns, how to prevent, detect and intervene if children are targets, preventing children from being cyber bullies, legal consequences and strategies to empower and also activate bystanders. ${ }^{78}$ Since most cyberbullying takes place at home, it's important that parents know about cyberbullying and that they get involved in preventing it. They must educate their kids about appropriate online behaviors just as they convey appropriate offline behaviors. They should also monitor their child's activities while online - especially early in their exploration of cyberspace. ${ }^{9}$

\section{Methods}

\subsection{Research procedures}

The sample of the study includes 200 pupils aged 15-19, 55 Male and 145 Female from High School's Elbasan.

Instrument used was "Student Needs Assessment Survey" APPENDIX E by N. E. Willard (2007). The questionnaire was modified and adapted by the authors and contains 20 items. Likert scale questions contain three alternatives ( 1 - Often to 3 - Never and Yes, 1 - 4 times to 3 - No) and four alternatives ( 1 - Often to 4 - I don't know and 1 - Most probably to 4 - No possibility) while other questions are categorical. Categorize the responses of pupils in the role of the knower of pressure on others and offer personal contribution to cooperate named in the three categories: harmful, neutral and successful.

The statistical data processing was performed by SPPS statistical program, version 20. Cronbach's Alpha .751. In completing questionnaire was maintained entirely pupils' anonymity.

\section{Discussion and Conclusion}

The data show that $73 \%$ of students use the Internet not only at school but also at home and $27 \%$ of them are not affected by it. During the week the subjects spend approximately less than 2 hours per day ( $34.5 \%$ of them), 2 hours per day ( $27 \%$ of them) and $20 \%$ of them more than 5 hours. The correlation between sex, frequency of Internet use at home and time spent during week is 0:01 significant level (2-tailed) and it shows that users of the Internet and its functions are men and women at the same time.

${ }^{3}$ O'Keeffe S. G., Pearson C. K., \& Council on Communications and Media (2011). Clinical Report - The Impact of Social Media on Children, Adolescents and Families. Pediatrics. Vol. 127, No. 4, $800-804$ pp.

${ }_{4}^{4}$ Mare'es von N., \& Petermann F. (2012). Cyberbullying: An increasing challenge for schools. School Psychology International Vol. 33 No. 5. $467-476 p p$

${ }^{5}$ Feinberg T., \& Robey N. (2010) Cyberbullying: Intervention and Prevention Strategies. National Association of School Psychologists. Vol. 38. No. 4, $22-24$ pp.

${ }^{6}$ Cassidy, W., Faucher, C., \& Jackson, M. (2013). Cyberbullying among youth: A comprehensive review of current international research and its implications and application to policy and practice, School Psychology International,Vol. 34, No. 6, 575-612pp

${ }^{7}$ Willard N. (2007) Educator's Guide to Cyberbullying and Cyberthreats. Center for Safe and Responsible Use of the Internet. 12p

${ }^{8}$ Popovic-Citic, B., Djuric, S., \& Cvetkovic, V. (2011). The prevalence of cyberbullying among adolescents: A case study of middle schools in Serbia. School Psychology International, Vol. 32, No. 4, 412-424pp

${ }^{9}$ Hinduja, S. \& Patchin, J. W. (2014). Cyberbullying: Identification, Prevention, and Response. Cyberbullying Research Center. www.cyberbullying.us 
Graphic Nr. 1: Approximately how many hours per day you use the Internet during the week?

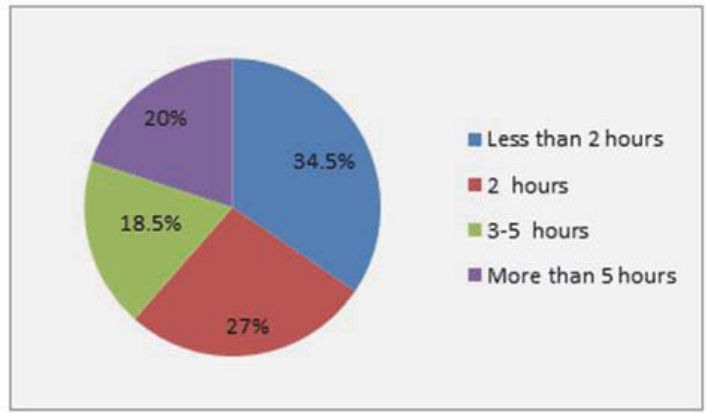

Table Nr. 1: Correlations between gender and time navigating on the Internet at home and during the week.

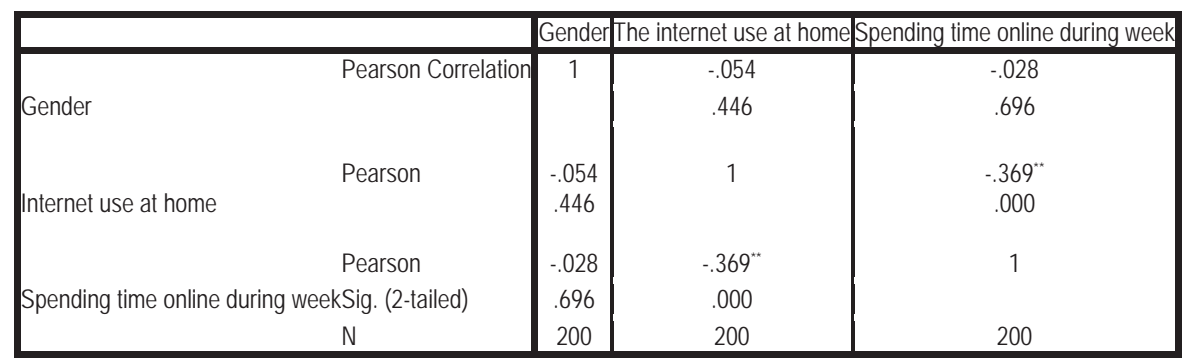

**. Correlation is significant at the 0.01 level (2-tailed).

Some of favorite concrete activities of students are: Surfing the Internet to see and learn new things (71\%), communication with school friends (65\%), making the homework with the help of the Internet (45.5\%), entertainment playing games (43\%), construction of the pages / profiles various Internet (13\%) and others. Referring phone use in school institution by students, $74 \%$ said they didn't use during the learning process and only $26 \%$ say that they use this communication tool.

Graphic Nr. 2: Favorite online activities chosen by pupils.

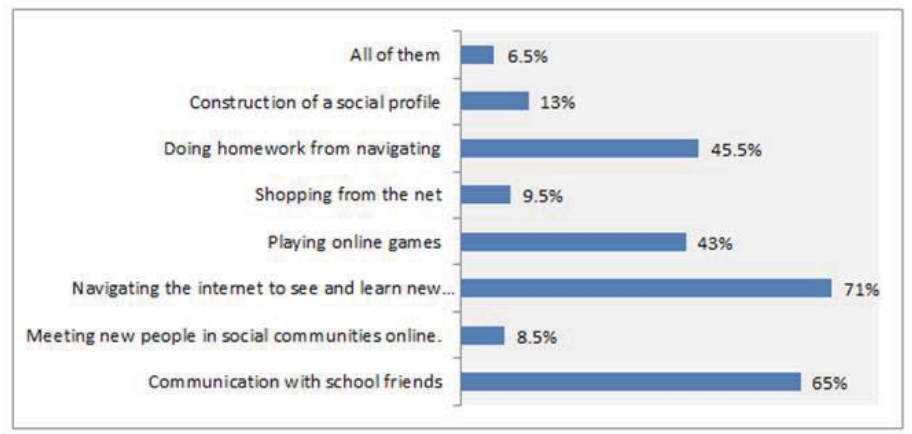


Graphic Nr. 3: Phone use in school institution by the pupils

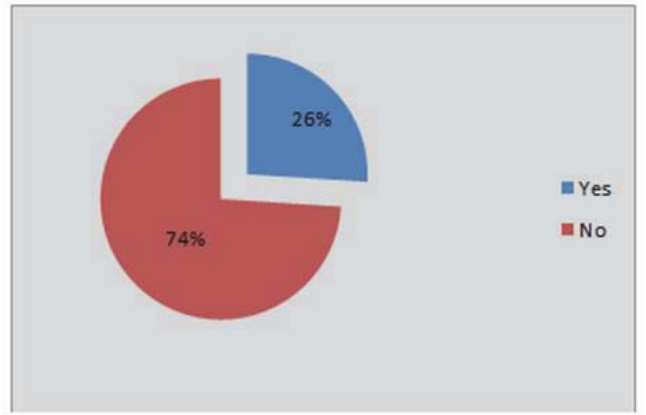

An important role in management of the use of internet functions of children is the parent, which considered as particular importance in the educational aspect and not only. Often parents think that if their children are at home using a computer they are safe, but it can happen that the child may be the target of a potential pressure from others or be the cause of any pressure. Communication between the parties is necessary because it helps in eliminating of a lot of problems caused by the Internet. The data show that $84.5 \%$ of students claim to have communication with their parents and $54 \%$ of students say that with the occasions have controls by their parents for what they do online.

Graphic Nr.4: Do your parents have talked about the way how you should treat your relatives?

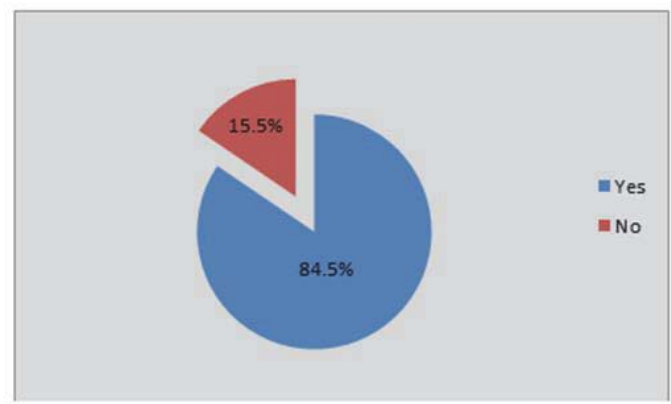

Graphic Nr. 5: Do you see your parents what you do online?

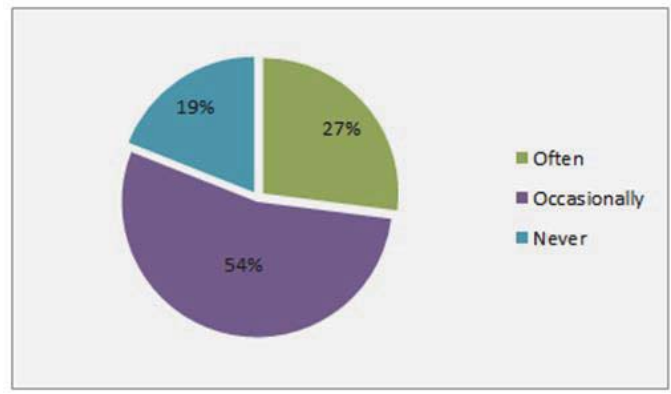

Turns out that $70.5 \%$ of student's use the most widespread social network Facebook, and $45 \%$ of them affirm that their profile sometimes or occasionally is seen by their parents, where $52 \%$ of them claim that they communicate with their parents about people who have friends in this social network, $31 \%$ of them communicate more often with the parents. 
Graphic Nr. 6: Do you have your own profile on any social network like Facebook for example?

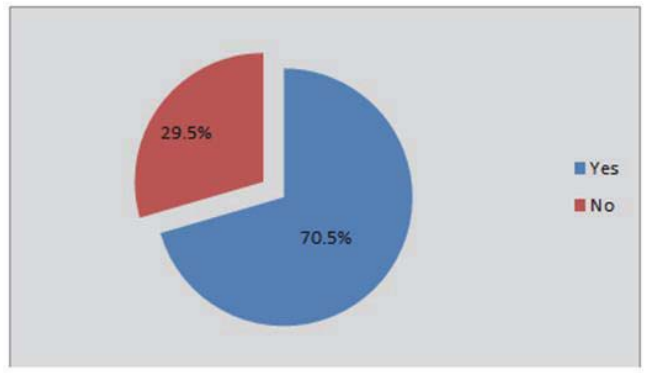

Graphic Nr. 7: Did your parents see this profile that you have?

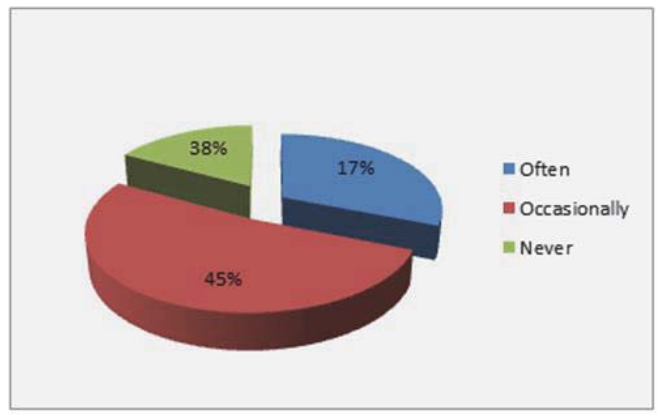

Graphic Nr. 8: Do you communicate with parents about people who have friends in this social network?

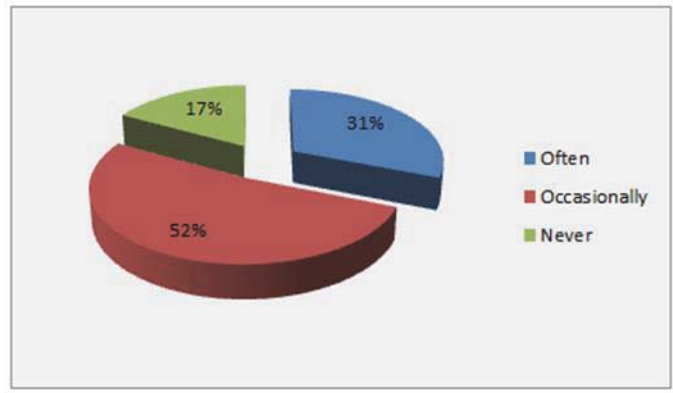

Relying situated in the role of one who puts pressure on the Internet to others, and the role of the person on whom are pressured by the results obtained we note that students are not included in any of above mentioned role. This means that they use the Internet by their peers is not the problem neither the psychological aspect of their teaching. 
Graphic Nr. 9: The role of the student as a person who exerts pressure on the Internet to others and as a person over who are pressured.

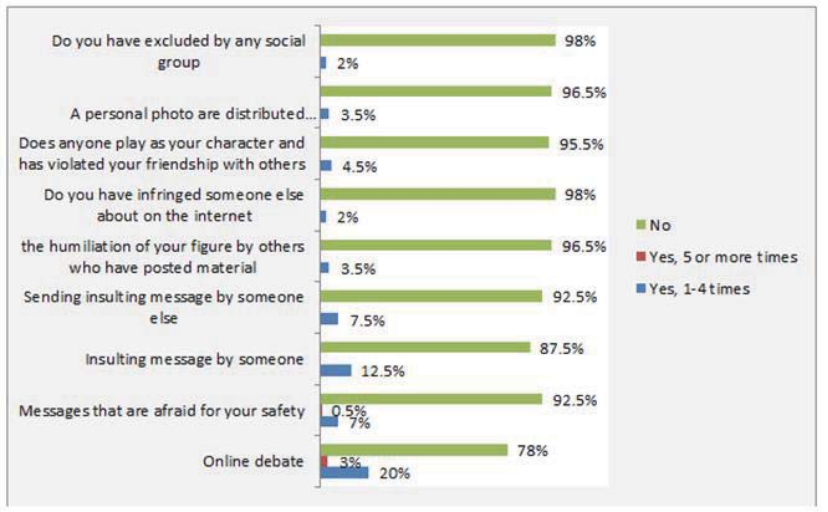

Students $(77.5 \%)$ claim that their peers do not feel pressured by others, only $21 \%$ of them felt under pressure 1-4 times. Also students (83.5\%) affirm that they are not aware of any material posted on the Internet that denigrates the image of a school staff member or a student who has posted on the Internet material that suggest the use of violence (83\%) or suicide (94\%). This shows that our school system managed effectively using the Internet and other communication tools.

Graphic Nr. 10: Do you think that your friends feel pressured class from the others in the Internet?

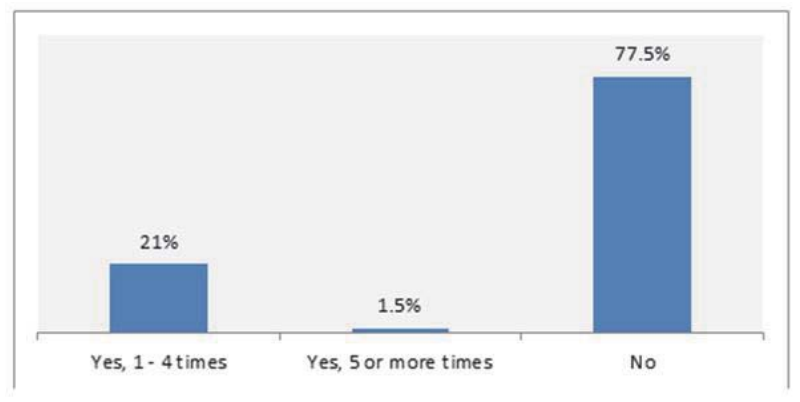

Graphic Nr. 11: Have you seen or are aware of any material posted on the Internet that denigrates the figure of any member of the school staff, which have threatened or suggested the use of violence or suicide.

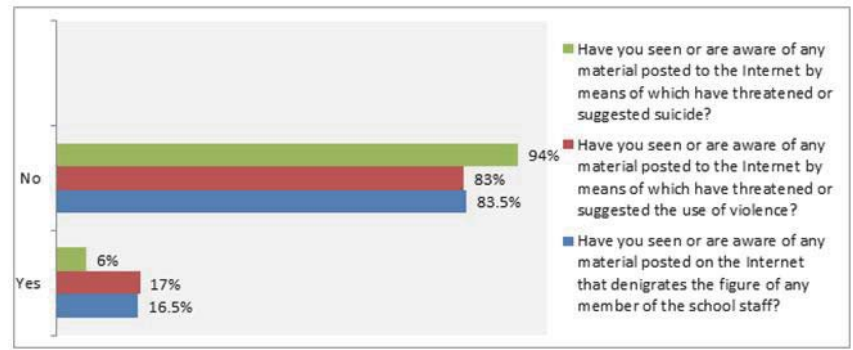

Referring to the use of computers of the school $71 \%$ of students claim they don't know if it happens online pressure when used school computers, $19 \%$ of them claim that never occurs pressure, $10 \%$ of them affirm that it happens occasionally. 
While referring other adequate electronic tools or mobile phones $48.5 \%$ of students say they do not know if the pressure occurs on the Internet when they use these electronic tools in the school environment, $34 \%$ of them claim that pressure sometimes occurs through the use of mobile phones, $11.5 \%$ say it happens often and only $6 \%$ say that never happens pressure.

Graphic Nr. 12: Do you think that happen online pressure when students use school computers?

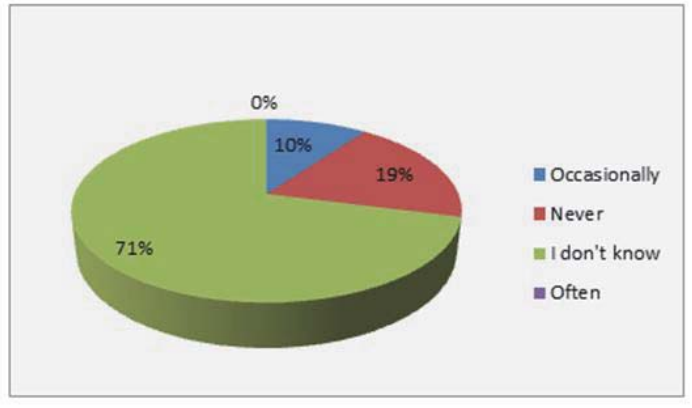

Graphic Nr. 13: How often do you think that the pressure on the internet via cell phones they use at school?

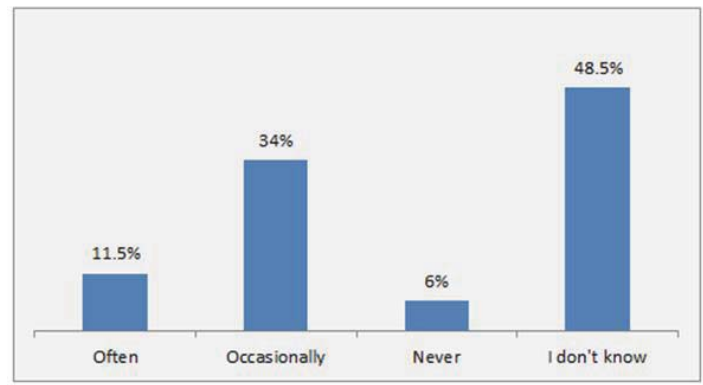

If students would be the victim of pressure on the Internet and will not have the opportunity to can be contained $77 \%$ of them indicated that they would approve of their parents and also (70.5\%) to school staff members, but even if they will see one of the their peer has become the victim of pressure (63\%) or that suggested violence or suicide (81\%) they were again collaborative with parents or with any member of the school staff. For the psycho-pedagogical point of view we can say that viewed a positive relationship and not only communication between children and their parents, but also among school staff.

Graphic Nr. 14: Students report referred pressures concerns freely online to parents and school staff.

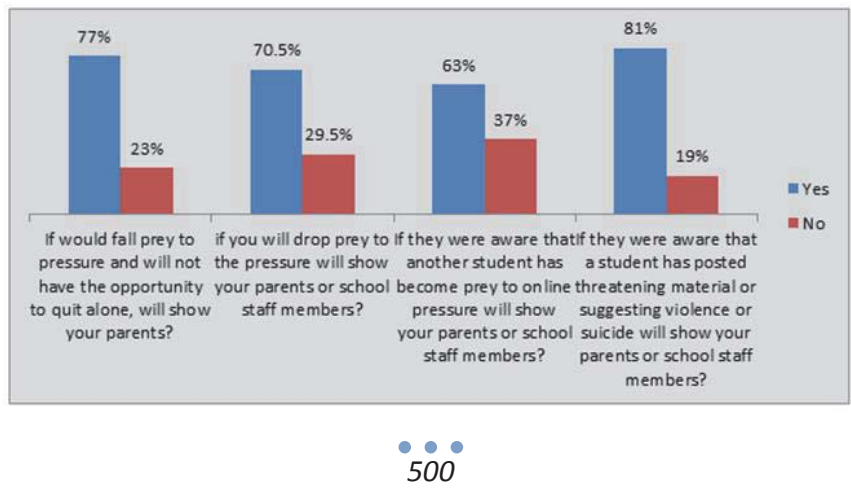


Table Nr. 2: Descriptive Statistics about reporting and support that offer student if they saw someone whose pressure is on the Internet become.

\begin{tabular}{|l|c|c|c|c|c|}
\hline & N & Minimum & Maximum & Mean & Std. Deviation \\
\hline Harmful & 200 & 1.50 & 4.00 & 3.7350 & .49852 \\
Neutral & 200 & 1.00 & 4.00 & 2.1050 & .87338 \\
Success in achieving the objectives & 200 & 1.00 & 4.00 & 2.2030 & .69383 \\
Valid N (listwise) & 200 & & & & \\
\hline
\end{tabular}

If students were going to see someone who is coming under pressure in the Internet they say that there is no opportunity for them to join pressure posting similar material, or to back the person who was making pressure $(m=3.73)$, which means that the risk level does not appear to cause violence by technology. Students appear to neutral levels around avoiding Cyberbullying $(m=2.1)$ even students report that will help their peers a little bit if they were the victim of pressure exerted by Internet users who denigrate their image $(m=2.2)$.

Recommend that it is necessary to maintain a school climate where bullying is less likely to take place and students feel comfortable reporting cyberbullying. Where incidents of cyberbullying are impacting on the learning of any student, schools will need to respond to these incidents, even if they occur out of school hours or on private equipment. The appropriate response will depend on the circumstances of the cyberbullying. It is necessary to be promoting antibullying messages throughout the school community. Schools will need to provide support to any student who is experiencing bullying, any student with bullying behaviors and any bystanders. Referring teachers they should know their students. Don't ignore or discount their situation by suggesting they ignore it or that it will stop on its own. Know their schools anti-bullying policies and reporting structures and establish an understanding of the existing evidence based approaches to dealing with cyber bullying. Develop an understanding of the role of bystanders in cyber space. Use the curriculum to support an investigation into cyber bullying. ${ }^{10}$

\section{References}

Cassidy, W., Faucher, C., \& Jackson, M. (2013). Cyberbullying among youth: A comprehensive review of current international research and its implications and application to policy and practice, School Psychology International,Vol. 34, No. 6, 575-612pp

Chao, C.M.; Yu, T.K. \& Cheng, B.W. (2013). Modeling predictors of adolescents' attitude towards a cyber lives index. Malaysian Journal of Library and Information Science, Vol. 18, No. 1, 87 - 104 pp.

Feinberg T. \& Robey N. (2010). Cyberbullying: Intervention and Prevention Strategies. National Association of School Psychologists. Vol. 38. No. 4, $22-24$ pp.

Hinduja, S. \& Patchin, J. W. (2014). Cyberbullying: Identification, Prevention, and Response. Cyberbullying Research Center [Online] Available: www.cyberbullying.us

Mare'es von N. \& Petermann F. (2012). Cyberbullying: An increasing challenge for schools. School Psychology International Vol. 33 No. $5.467-476 \mathrm{pp}$

O'Keeffe S. G., Pearson C. K., \& Council on Communications and Media (2011). Clinical Report - The Impact of Social Media on Children, Adolescents and Families. Pediatrics. Vol. 127, No. 4, $800-804$ pp.

Popovic-Citic, B., Djuric, S., \& Cvetkovic, V. (2011). The prevalence of cyberbullying among adolescents: A case study of middle schools in Serbia. School Psychology International, Vol. 32, No. 4, 412-424pp

Sonhera, N., E. Kritzinger \& M. Loock. (2012). A proposed cyber threat incident handling framework for schools in South Africa. Proceedings of the South African Institute for Computer Scientists and Information Technologists Conference on SAICSIT 12.

Valkenburg M. P. \& Peter J. (2009). Social Consequences of the Internet for Adolescents: A Decade of Research. Current Directions in Psychological Science Vol. 18, No. 1, 1-5 pp.

Willard N. (2007) Educator's Guide to Cyberbullying and Cyberthreats. Center for Safe and Responsible Use of the Internet. 12p

10 Sonhera, N., E. Kritzinger \& M. Loock. (2012). A proposed cyber threat incident handling framework for schools in South Africa. Proceedings of the South African Institute for Computer Scientists and Information Technologists Conference on SAICSIT 12. 